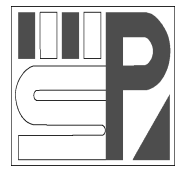

Science Press
Journal of Arid Land

2012, 4(4): 399-410

doi: 10.3724/SP.J.1227.2012.00399

jal.xjegi.com; www.chinasciencejournal.com

\title{
Impact of agricultural development on variation in surface runoff in arid regions: a case of the Aksu River Basin
}

\author{
XinHuan ZHANG $^{1 *}$, DeGang YANG ${ }^{1}$, XinYi XIANG ${ }^{2}$, Xiang HUANG ${ }^{1}$ \\ ${ }^{1}$ Xinjiang Institute of Ecology and Geography, Chinese Academy of Sciences, Urumqi 830011, China; \\ ${ }^{2}$ School of Geographical Sciences, Southwest University, Chongqing 400715, China
}

\begin{abstract}
Located in the south of Xinjiang Uygur autonomous region, the Tarim River is the longest inland river in China. Agricultural development, excessive exploitation and low surface water use efficiency in the headstream regions have led to a marked decrease in the water supply to the mainstream. This, in turn, has resulted in the drying-up of the watercourse in the lower reaches of the Tarim River and serious deterioration of the eco-environment. The Aksu River Basin, the most important headstream of the Tarim River, was selected as the research area in this study. Taking elastic coefficient, water demand coefficient and water utilization intensity as the indices, we studied the impact of agricultural development on decreasing surface runoff since the 1950s. The results indicated that (1) the increasing rate of consumption of surface runoff outstripped the rate of increase measured in the natural catchment discharge, resulting in ever diminishing stream discharge into the Tarim River. Agricultural irrigation and seepage loss in irrigation canal systems were the major sources for runoff consumption, taking $63.72 \%$ of the overall runoff consumption. What's more, agricultural water consumption took up more than $97 \%$ of the water used for long-term production; (2) the expansion of cultivated land, change of planting structure and comparatively low agricultural irrigation efficiency all contributed to the decrease in surface runoff of the Aksu River. The elasticity coefficient of surface runoff reduction corresponding to the increase in planted area was 0.34 in the 1950s, while in the 2000s it had increased to 7.87 . This reflected a more sensitive response of runoff decrease to cultivated land expansion. The increase in cotton and fruit production, without widely-used scientific irrigation methods and water-saving technology, led to considerable waste of the water resources. Meanwhile, the irrigation efficiency was still quite low, characterized by the waste of water resources, and the decrease of surface runoff; (3) in different stages, cultivated land area, planting structure and agricultural water use efficiency exerted different effects on runoff decrease. In the early stage, agricultural development showed no obvious effect on runoff decrease. Since the 1960s, the expansion in cultivated land resulted in large consumption of surface runoff; since the 1990s, not only expansion in cultivated land expansion, but also planting structure exerted significant impact on the consumption of surface runoff. Recently, though agricultural water use efficiency has improved in some regions to reduce the consumption of runoff to a certain extent, overall agricultural water use efficiency is still quite low; (4) during the investigation period, water consumption by agricultural development reflected the unbalanced relationship between human activities and water resources.
\end{abstract}

Keywords: agricultural water use efficiency; cultivated land area; planting structure; surface runoff variation; Aksu River Basin

Located in the south of Xinjiang Uygur autonomous region, the Tarim River is the longest inland river in China. The Tarim River Basin is characterized by both rich natural resources and fragile environments (Jiang et al., 2007), and takes an important position in the development of Xinjiang (Chen et al., 2005). The Tarim River is a purely dissipative inland river producing no runoff, and completely relies on water sup-

Received 2012-01-17; accepted 2012-08-06

"Corresponding author: XinHuan ZHANG (E-mail: zhangxh@ms.xjb.ac.cn) 
ply from its headstreams in the mountains around the Tarim Basin (Yu et al., 2011). Currently, there are four headstreams in this watershed, namely the Hotan, the Yarkant, the Aksu and the Kaidu-Konqi rivers (Fig. 1). The utilization of water resources in the headstreams, which impacts on the variation of river water in the mainstream, plays a significant role in the eco-environment in the lower reaches of the Tarim River (Chen et al., 2003; Deng, 2005). In the last several decades the water supply from the headstreams to the mainstream has decreased markedly under the impact of social and economic activities characterized by over-exploitation of water resources. This has led to the drying-up of the river course in the lower reaches of the Tarim River (Ye et al., 2010; Ma et al., 2011). Additionally, in the lower reaches, the lakes dried up and groundwater levels fell noticeably. Riparian vegetation, Populus euphratica forest as the dominant species showed an overall degradation; desertification was accelerated and biological diversity was seriously damaged (Chen et al., 2006a; Zuo, 2006; Chen et al., 2008). The important green corridor in the lower reaches of the River was almost destroyed (Song et al., 1999; Li et al., 2006).
Considering the eco-environmental problems in the process of water resource exploitation and utilization in the Tarim River Basin, many researchers have already carried out numerous studies on the surface runoff variation. It was found that while the surface runoff of the headstreams of Tarim River showed significant increase under the influence of climate, the water flowing in the mainstream of Tarim River from the headstreams decreased continuously (Chen et al., 2006b). It was demonstrated that human activities such as irrigation dominated the stream flow changes in this river (Hao et al., 2008). It was recognized that agricultural development was a major reason for the water resource crisis in the Tarim River Basin (Zhu et al., 2001). With rapid economic development, which mainly relied on the expansion of agricultural production, the cultivated land area in the headstreams of the Tarim River increased continuously and the water consumption for irrigation increased accordingly (Gou et al., 2010; Mansue et al., 2011). The rapid expansion of cultivated land led to increased consumption of surface water resources, with irrigation depending both on direct diversion of river water and on water stored in reservoirs. The rate of surface water exploitation of Aksu River, Hotan River, and Yarkant River were

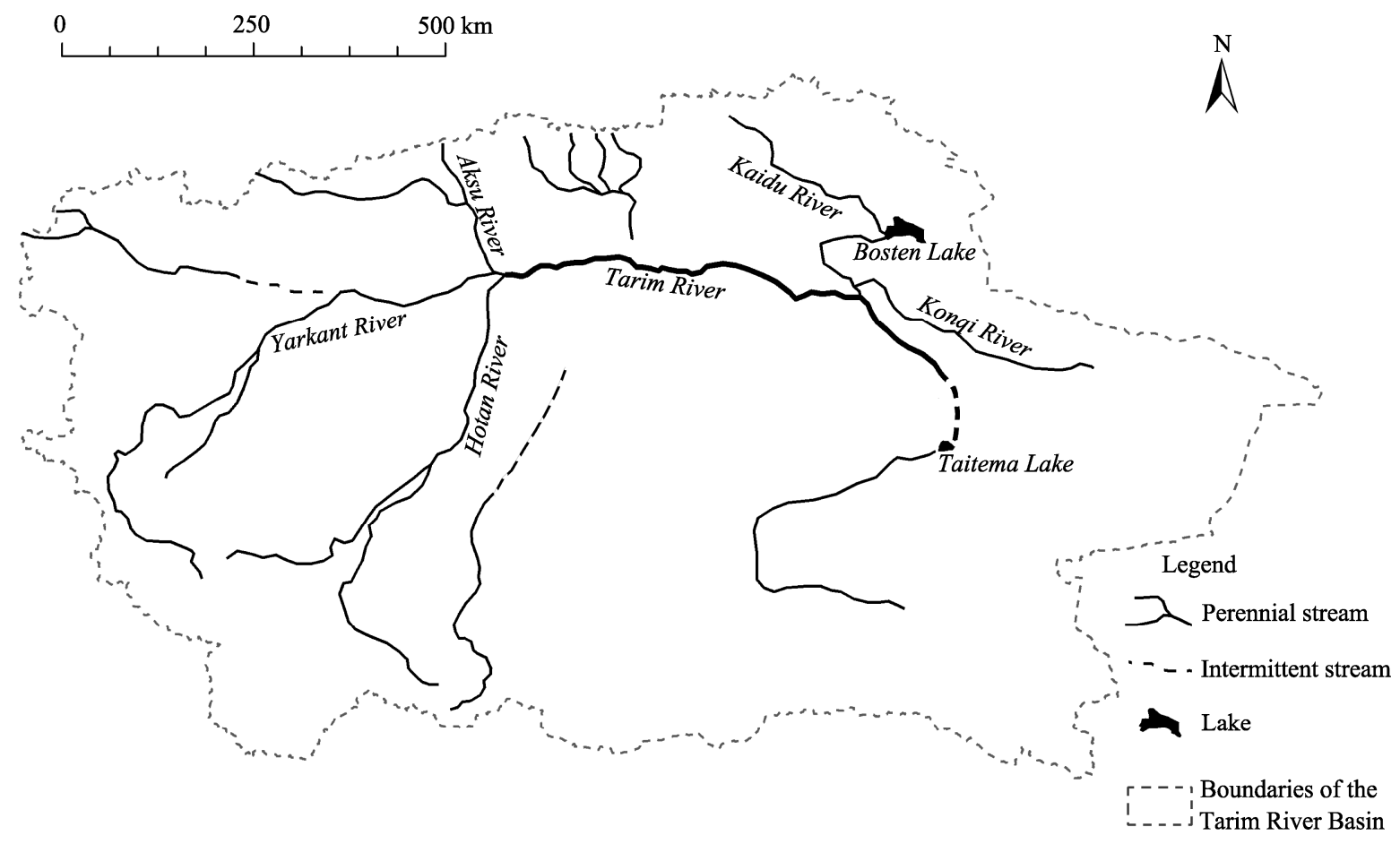

Fig. 1 Sketch map of Tarim River Basin 
$59.4 \%, \quad 70.6 \%$ and $87.3 \%$, respectively in 2004 (Mtalip et al., 2009). Excessive exploitation and low water use efficiency of surface water in agricultural development in the headstream regions led to obvious decreases in the water supply to the mainstream (Duan et al., 2001; Xu et al., 2008; Wang et al., 2009), which eventually resulted in the drying-up of the watercourse in the lower reaches of the Tarim River and serious deterioration of the eco-environment (Chen et al., 2009; Wang et al., 2010). Since the implementation of the project of water conveyance to the dried-up river course, ecological restoration has been realized step by step, but shortage of water to convey to the downstream of Tarim River was still believed to be the key problem by researchers and managers (Chen et al., 2004; Chen et al., 2007). Agricultural development, consuming most of the surface water in the headstream and the upstream areas, has undoubtedly become the major factor constraining the success of the water conveyance project. The impact of agricultural development on changes to surface runoff is an urgent scientific problem to be addressed. In this paper, the Aksu River Basin, the most important headstream area of the Tarim River, was selected as the study area. Specific impacts of agricultural development on surface runoff in the Aksu River were studied from three aspects, namely the scale of the cultivated land area, the planting structure and agricultural water use efficiency. The study aimed to obtain a clear understanding of the mechanism involved in the above factors influencing the consumption of surface runoff in different stages, which will reflect the relationship between human activities and water resources in this arid land.

\section{Study area and methods}

\subsection{Study area}

The Aksu River offers $73.2 \%$ of the surface water supply to the Tarim River, and it has been very important in the formation and evolution of the Tarim River (Jiang et al., 2005; Fu et al., 2009), as well as in the sustainable development within the Tarim River Basin (Zhang et al., 2008). Accordingly, the Aksu River Basin was selected to investigate the impact of agricultural development on the variation in surface runoff.

The Aksu River Basin is located in the west of the middle part of the Tianshan Mountains (Fig. 1), to the northwest of the Tarim Basin of China $\left(40^{\circ} 14^{\prime} 11^{\prime \prime} \mathrm{N}-\right.$ $\left.42^{\circ} 27^{\prime} 42^{\prime \prime} \mathrm{N}, 75^{\circ} 33^{\prime} 16^{\prime \prime} \mathrm{E}-80^{\circ} 59^{\prime} 07^{\prime \prime} \mathrm{E}\right)$. This region is dominated by the temperate continental arid climate, with the annual mean temperature ranging from $9.2^{\circ} \mathrm{C}$ to $11.5^{\circ} \mathrm{C}$, and the mean annual precipitation and mean annual potential evaporation being 63 and 1,632 $\mathrm{mm}$, respectively. There are two different administrative departments in this basin, namely Aksu Administrative Offices (AAO) and the First Agricultural Division (FAD) under the management of Xinjiang Production and Construction Corps, which has been a specific production organization in Xinjiang since 1954. Cultivated land in the oases in the Aksu River Basin expanded rapidly in the last 50 years to make the Basin become one of the most important production bases for grains, cotton and fruits in Xinjiang. Water diversion from watercourses increased and water discharge to the mainstream of the Tarim River decreased accordingly, which seriously constrained economic development and had an enormous negative effect on the eco-environment in the middle and lower reaches of the mainstream of Tarim River.

\subsection{Methods}

\subsubsection{Elasticity coefficient}

Using the elasticity concept in economics (Paul and William, 2004), the study analyzed the surface runoff reduction percentage corresponding to $1 \%$ growth of cultivated land in the Aksu River Basin, which was then used to determine the degree of response of surface runoff consumption to cultivated land expansion, with the equation listed below:

$$
E=\frac{\left(R_{2}-R_{1}\right) / R_{1}}{\left(A_{2}-A_{1}\right) / A_{1}} .
$$

Where, $R_{1}$ is the surface runoff consumption in the former stage, and $R_{2}$ is the surface runoff consumption in the latter stage; $A_{1}$ is the area of the cultivated land in the former stage, and $A_{2}$ is the area of the cultivated land in the latter stage, and $E$ is the elasticity coefficient. If $0<E<1$, it means that when the increase of cultivated land area is $1 \%$, surface runoff reduction is less than $1 \%$, which indicates surface runoff variation is not sensitive to cultivated land expansion; if $1 \leq E<$ $\propto$, it means that when the increase of cultivated land area is $1 \%$, surface runoff reduction is greater than or equal to $1 \%$, which indicates surface runoff variation is sensitive to cultivated land expansion. 
1.2.2 Water demand coefficient of cultivated land

For analyzing the water demand difference generated from the planting structure of cultivated land, the water demand coefficient of cultivated land under the impact of planting structure was defined as follows:

$$
Q=\frac{\sum_{1}^{i} d_{i} S_{i}}{A} .
$$

Where, $d_{i}$ is the ratio of the theoretical irrigation quota of crop $i$ to that of wheat; $S_{i}$ is the planting area of crop $i$; $A$ is the total area of the cultivated land; and $Q$ is the water demand coefficient of cultivated land. With the same irrigation level, for lands of the same area, the higher the $Q$ value is, the more water the plants consume, and the higher the actual water demand for irrigation is.

\subsubsection{Agricultural water utilization intensity}

Considering both the water consumption per unit of cultivated land area and the water consumption per unit of agricultural output value, agricultural water utilization intensity was defined as follows:

$$
W_{e}=\sqrt{(C / A) \times(C / G)} .
$$

Where, $C$ is the total irrigation volume; $A$ is the cultivated land area; $G$ is the agricultural output value which was calculated at 1990 constant prices; and $W_{e}$ is the agricultural water utilization intensity. The lower the $W_{e}$ is, the higher the agricultural water use efficiency is.

\subsection{Data source}

The data for agricultural development and agricultural water use were obtained from Xinjiang Statistical Yearbooks (Statistical Bureau of Xinjiang Uygur Autonomous Region, 1981-2010), Statistical Yearbooks from 1955 to 2005 of Xinjiang Uygur autonomous region (Statistical Bureau of Xinjiang Uygur
Autonomous Region, 2005), Statistical Yearbooks of Xinjiang Production and Construction Corps (Statistics Bureau of Xinjiang Production and Construction Corps, 1990-2010), Statistical Yearbooks for the Aksu region (Administrative Office of Aksu Region and Statistics Bureau of Aksu Region, 2000-2010), and Xinjiang Water Resource Bulletins for the corresponding years (Water Resources Bureau in Xinjiang Uygur Autonomous Region, 2007-2010).

\section{Results}

\subsection{Surface runoff consumption}

The surface runoff in the Aksu River Basin was formed from precipitation and meltwater in high mountain regions. Downstream of the streams running through the mountain pass, water was redistributed through state transition among atmospheric water, surface water, soil water and ground water $(\mathrm{Xu}$ et al., 2005). A large amount of surface runoff provides irrigation water for oasis agriculture formed on alluvial plains (Wang et al., 1998; Yang et al., 2004), and the remaining part of the surface runoff runs into the mainstream of the Tarim River.

The inter-decadal variations in the data (Table 1) indicated that there was an increasing trend in natural discharge within the Aksu River Basin. However, because of the obvious increase in water consumption inside the Basin, water discharge into the mainstream of the Tarim River decreased significantly. Especially during the period from 2000 to 2009, the natural discharge flow of the Aksu River attained its maximum value, which was 2.08 times the value ten years' before, but water discharge into the mainstream of the Aksu River was the minimum it had been over the preceding 6 decades, and only $78 \%$ of the value for the previous decade.

\begin{tabular}{|c|c|c|c|}
\hline Period & $\begin{array}{l}\text { Natural discharge flow } \\
\qquad\left(10^{8} \mathrm{~m}^{3}\right)\end{array}$ & $\begin{array}{l}\text { Flow discharge into the mainstream of } \\
\text { Tarim River }\left(10^{8} \mathrm{~m}^{3}\right)\end{array}$ & $\begin{array}{l}\text { Water consumption before discharge into the } \\
\text { mainstream of Tarim River }\left(10^{8} \mathrm{~m}^{3}\right)\end{array}$ \\
\hline 1957-1959 & 66.74 & 30.25 & 36.49 \\
\hline 1960-1969 & 79.34 & 36.98 & 42.36 \\
\hline 1970-1979 & 77.5 & 31.16 & 46.34 \\
\hline 1980-1989 & 78.35 & 33.70 & 44.65 \\
\hline 1990-1999 & 92.36 & 34.09 & 58.27 \\
\hline $2000-2009$ & 192.00 & 26.85 & 165.15 \\
\hline Average (53 a) & 82.95 & 32.41 & 50.54 \\
\hline
\end{tabular}

Table 1 Surface runoff and water consumption of Aksu River in different stages 
Table 2 Percentage of the primary industry water consumption in the Aksu River Basin

\begin{tabular}{cccc}
\hline Year & $\begin{array}{c}\text { Percentage of the primary industry water } \\
\text { consumption in total productive water } \\
\text { consumption (\%) }\end{array}$ & $\begin{array}{c}\text { Percentage of farming irrigation water consump- Percentage of water consumption for forestry, } \\
\text { tion in the primary industry water consumption } \\
(\%)\end{array}$ & $\begin{array}{c}\text { animal husbandry and fisheries in the primary } \\
\text { industry water consumption }(\%)\end{array}$ \\
\hline 1980 & 99.11 & 84.35 & 15.65 \\
1985 & 99.02 & 84.01 & 15.99 \\
1990 & 98.40 & 79.18 & 20.82 \\
1995 & 98.19 & 76.21 & 23.79 \\
2000 & 98.36 & 76.71 & 23.29 \\
2005 & 98.37 & 75.76 & 24.24 \\
2009 & 97.71 & 75.00 & 25.00 \\
\hline
\end{tabular}

There are both productive consumption and non-productive consumption for the surface runoff of Aksu River. The former is the water consumption by social and economic development, and the latter is water consumption by ecological and other natural processes (Wang et al., 2008). The total amount of water consumption in the Aksu River, has been apportioned as agricultural water consumption of $34.98 \%$, industrial water consumption, human and livestock drinking water of $2.4 \%$, water loss in river of $20.71 \%$, seepage and evapotranspiration losses in irrigation canals of $28.74 \%$ and the consumption in reservoirs, lakes and wetlands of $13.16 \%$ (Deng, 2009). Among the forms of productive water consumption (Table 2), water consumption for the primary industry took up more than $97 \%$ for a long time, which was composed of the water consumption for farming and that for forestry, animal husbandry and fisheries. The percentage attributed to consumption for farming decreased from $84.35 \%$ in 1980 to $75 \%$ in 2009 , while percentage of the water consumption for forestry, animal husbandry and fisheries increased rapidly.

\subsection{Situation of agricultural development}

Since 1950, expansion in the area of cultivated land has been the trend in the Aksu River Basin, among which, increase in the cultivated land under FAD control was significant in the whole Basin. The percentage of cultivated land of FAD increased from $2.20 \%$ in 1950 to $25.51 \%$ in 2009 (Fig. 2). An obvious change was also found in planting structure: before 1985, the proportion of grain planting area in cultivated land was highest; since 1985, the proportion of cotton planting area has increased, and in 1997 the proportion of cotton planting went higher than that of grain cultivation. Since 2000 the area of forest fruit planting has increased quickly, and in 2009 its planted area was almost the same as that of grain planting (Fig. 3). Overall, agricultural development in the Basin has been characterized recently as cotton planting taking the largest area, the area of forest fruit planting showing an increasing tendency, and the area of grain cultivation decreasing gradually.

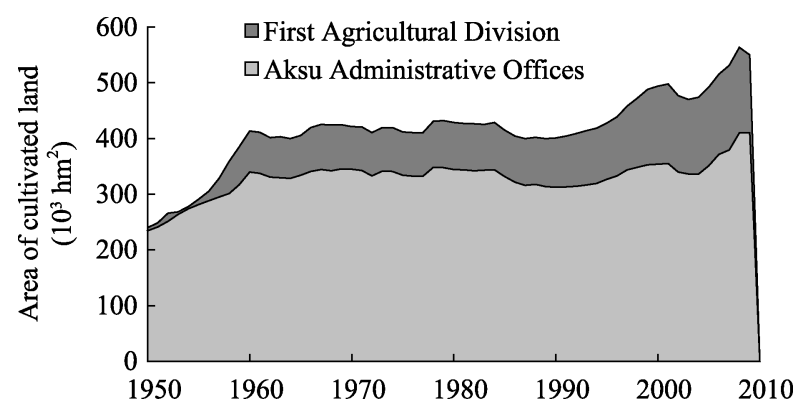

Fig. 2 Changes of cultivated land area in the Aksu River Basin

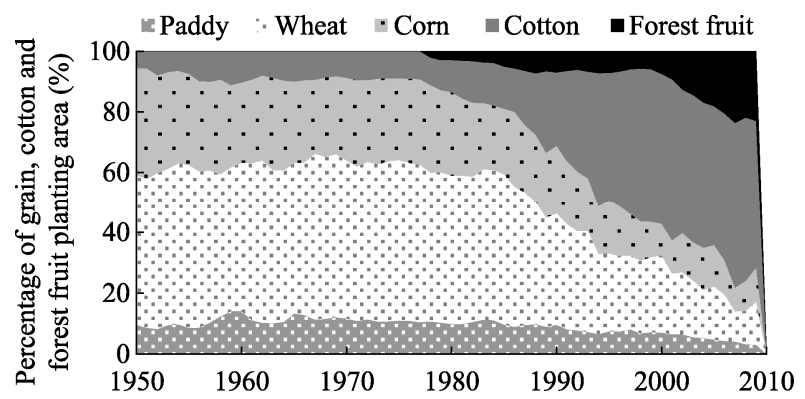

Fig. 3 Changes of planting structure in the Aksu River Basin 


\subsection{Impact of agricultural development on surface runoff reduction}

2.3.1 Effect of increase in planting area on surface runoff consumption

As the above analysis revealed, $63.72 \%$ of the surface runoff consumption in the Aksu River Basin has been taken up by agricultural development and losses in irrigation channels. Thus the development of agriculture has been the major cause for the obvious reduction of surface runoff. By comparison, under certain conditions, the non-productive water consumption by river course, lakes, reservoirs and low-lying wetlands was stable (Wang et al., 2010).

An elasticity coefficient was introduced to analyze variation in surface runoff consumption corresponding to increases in planting area (Fig. 4). Before the 1970s, the elasticity coefficient of runoff reduction corresponding to the planting area increase was below 1 , indicating the response of runoff reduction to planting area increase was weak. During the period from 1980 to 1989 , the elasticity coefficient of runoff reduction corresponding to planting area increase was 1.06 , indicating a comparatively obvious relationship between increase in planting area and reduction in runoff. Since the 1990s, the elasticity coefficient of runoff reduction corresponding to planting area has been far more than 1 , with the highest value reaching 7.87 , indicating a strong response of runoff consumption to planting area.

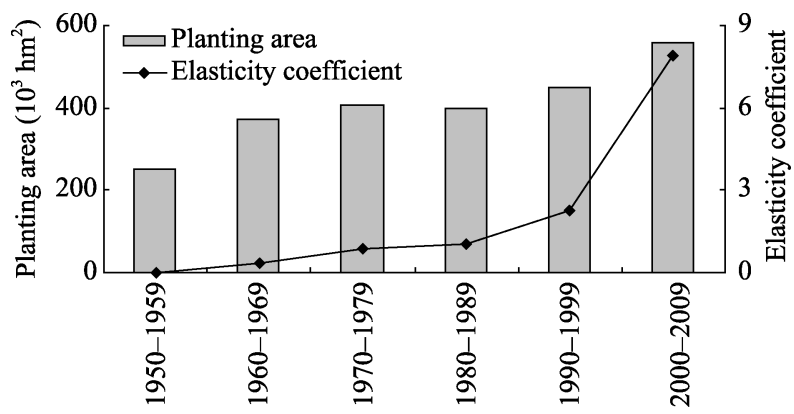

Fig. 4 Elasticity coefficient of water consumption corresponding to total planting area

2.3.2 Variation of water consumption demand to planting structure change

A water demand coefficient for cultivated land was used to analyze water demand variation corresponding to changes in the proportions of areas for the planting of different crops (Fig. 5). It was shown that if only the major crops of paddy, wheat, corn and cotton were taken into consideration, then, since 1985 , cultivated land water demand coefficient has increased significantly. From the aspect of agricultural structure (Fig. 2 ), variations in the proportion of the agricultural area planted with paddy were small, but the proportion of wheat and corn planting decreased rapidly in this period. What's more, the cotton planting area increased significantly. According to the theoretical surface-irrigation schedule in the Aksu River Basin (Water Resources Bureau in Xinjiang Uygur autonomous region, 1993), the irrigation quota of cotton $\left(5,100 \mathrm{~m}^{3} / \mathrm{hm}^{2}\right)$ was higher than that of wheat $\left(4,200 \mathrm{~m}^{3} / \mathrm{hm}^{2}\right)$ and corn $\left(4,650 \mathrm{~m}^{3} / \mathrm{hm}^{2}\right)$. Increases in the area of high water-consuming crops led to large increases in water demand. Further, taking forest fruit planting into consideration, it was found there were two sharp increases in water demand coefficient for cultivated land in 1985 and in 2000. The increase in 1985 was mainly caused by the increase in the area and proportion of cotton planting, while the increase in 2000 was mainly caused by the rapid expansion in the area of forest fruit planting, the irrigation quota of which in the schedule of theoretical surface-irrigation was 5,100 $\mathrm{m}^{3} / \mathrm{hm}^{2}$.

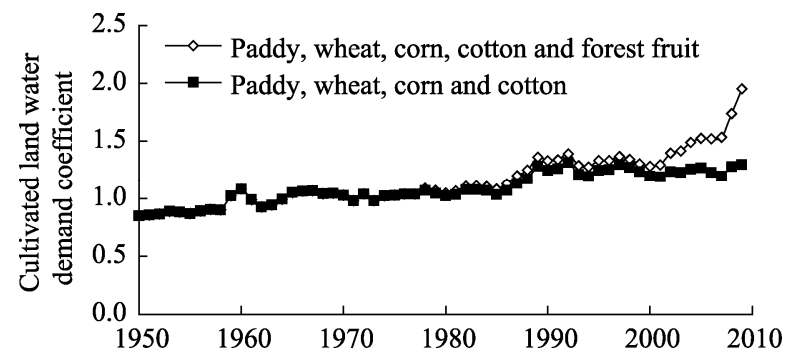

Fig. 5 Variation in water demand coefficient of cultivated land in the Aksu River Basin

2.3.3 Low agricultural water utilization efficiency leading to extremely high surface runoff consumption

Due to the increase of agricultural water consumption, several countermeasures were applied to improve the efficiency of agricultural water use to deal with the problem of water resource constraint. Since 1980, 
there has been a significant decrease in the intensity of agricultural water use (Fig. 6), indicating the improvement in agricultural water use efficiency. By investigating the two factors governing the intensity of agricultural water use it was clear that reduction in water consumption per unit of agricultural output or value was far more than the reduction per unit of cultivated land area (Fig. 7). This indicates that agricultural economic growth had a significant influence on the improvement in the agricultural water use efficiency, while water saving measures had no obvious effect on water use efficiency. Further, water use efficiency in the Aksu River Basin has lagged behind the average level for Xinjiang in the same period, reflecting a large potential for water saving in this basin.

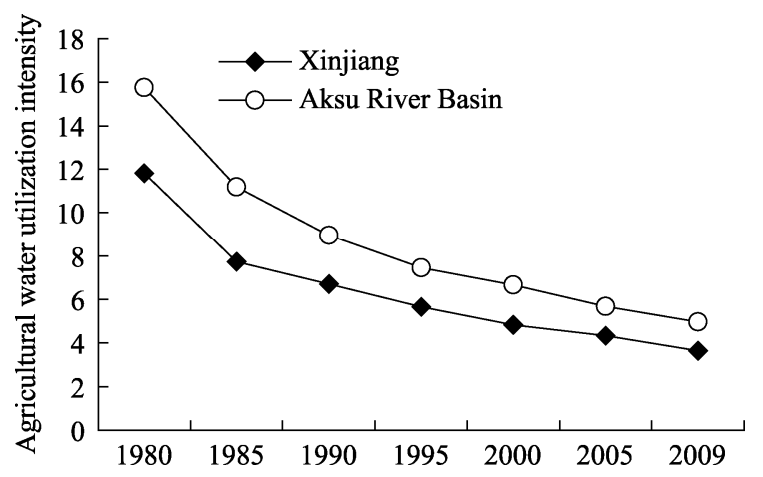

Fig. 6 Agricultural water use intensity in the Aksu River Basin

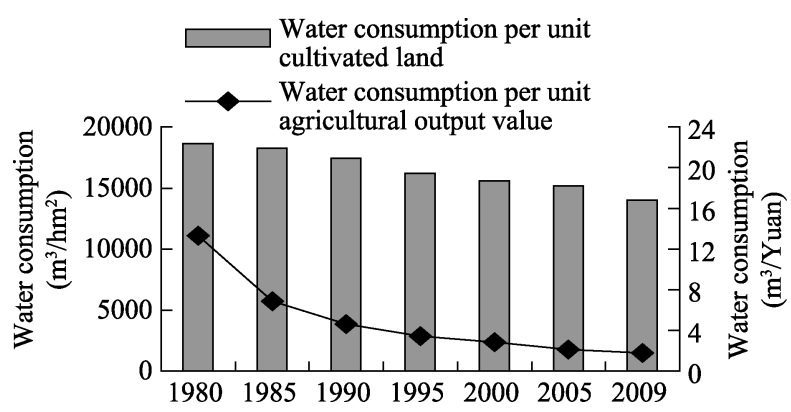

Fig. 7 Water demand per unit cultivated land area and water demand per unit output value in the Aksu River Basin

\section{Discussion}

With global climatic change and the large-scale exploitation of water resources, the surface runoff is under significant change, which goes beyond the annual and inter-annual variations and reflects the effect of human activities. The variation of runoff into the
Tarim River is a complex system problem with multilevels and multi-factors (Wang et al., 2010). Hao et al. (2008) reported that during the 1970s, 1980s, 1990s and 2000-2005 annual runoff reductions in the main stream in the Tarim River induced by human factors were $41.96 \%, 74.73 \%, 76.45 \%$ and $67.18 \%$, respectively. Based on principal component analysis, Chen et al. (2011) reported that effective irrigation area, agricultural population, cultivated land area and the proportion of the primary industry had strong influences on the decreased runoff in the mainstream of the Tarim River. The process of farmland development in the headstream area, irrigation area expansion and the style of extensive water utilization led to great interception of water in those headstreams (Zhou et al., 2008). Further, lack of embankment and water-diversion projects in the mainstream of the Tarim River led to seriously disorganized water diversion and serious water wastage, resulting in reduction in the discharge from the upstream to the middle stream (Xi et $a l ., 2009)$. Existing research has identified the significant effect of agricultural development on runoff reduction in the Tarim River Basin. Based on these findings, the study quantitatively analyzed the scale of cultivated land area, proportions of major crops and agricultural water use efficiency, to explore the influence, mechanism and the stage characteristics of the agricultural development on runoff variation. The results of this study are helpful in revealing the evolution of the characteristics and relationship between human activities and water resources.

\subsection{The mechanism of the influence of agricultural development on runoff variation in the Aksu River Basin}

When the flow of natural runoff ran into the plain irrigation area, the runoff clearly decreased with the increase of irrigation water consumption in the process of cultivated land expansion (Chen, 2008). On the one hand, crop growth consumed water directly. On the other hand, evaporation and leakage in irrigation canals led to considerable water loss ( $\mathrm{Yu}$ et al., 2009). As a result, the increase of cultivated land area was the primary driving factor for runoff consumption. In this study, it was found that the sensitivity of surface runoff reduction increased gradually in response to the 
variation in planting area. In the $1950 \mathrm{~s}$, the increase of runoff reduction was only $0.34 \%$ for each $1 \%$ increase in cropping area; while in the $2000 \mathrm{~s}$, the increase of runoff reduction was as high as $7.87 \%$ for each $1 \%$ increase of cropping area. The change in the mix of major crops planted contributed to the increasing trend in the relation between runoff reduction and increase in cropping area. As a water-consuming system, cultivated land was used for the planting of different kinds of crops. If the areas of cultivated land and water use efficiency were keep constant, an increase in the proportion of high water-consuming crops would lead to an increase in water consumption. In the Aksu River Basin, farmers receive higher economic benefits by planting cotton and fruits, which has led to an increase in the proportion of land planted with cotton and fruits (Fig. 3). The expansion in the area of these high water-consuming crops without wide application of scientific irrigation and water-saving technology has resulted in the continuous decrease in surface runoff. The low irrigation efficiency has led to serious waste of water resources, which also contributed to surface runoff reduction. In this basin, water consumption per unit of cultivated land was quite high, reaching 14,008 $\mathrm{m}^{3} / \mathrm{hm}^{2}$ in 2009, 1.62 times the average value in Xinjiang. Agricultural water use efficiency was low and water consumption per unit of cultivated land area was especially high, reflecting agricultural development in an extensive pattern. With this development pattern, obtaining high agricultural economic benefits depended on large-scale exploitation of water resources, which eventually led to the rapid reduction of the surface runoff in the Aksu River Basin.

\subsection{Stage characteristics of the effect of agricul- tural development on runoff consumption in the Aksu River Basin}

Based on the influence of expanding cultivated land area, proportions of crops grown and water use efficiency on surface runoff, the study summarized the effects of agricultural development on runoff variation in different stages as follows:

(1) Years 1949-1957 (stage with weak influence): This was the forerunner to large scale reclamation, with the guideline of making grain the key crop in China (Mao, 1998). In this period, there was an obvi- ous increase in cultivated land area, with $119.51 \mathrm{hm}^{2}$ increase in 8 years. Grain planting was dominant. Farmland irrigation was practiced by direct water diversion from watercourses. There were rarely leakage-proof measures in channels, and flood irrigation was the major style. Based on the abundant water resources in the Aksu River relative to the total cultivated land area at that time, the farmland area employing extensive irrigation increased rapidly, but with agricultural development exerting only a weak influence on surface runoff reduction. Consumption of surface runoff was mainly non-productive, such as ecological water demand, water surface evaporation and seepage.

(2) Years 1958-1984 (stage with preliminary influence): During the later period (1958-1965) of large scale reclamation promoted by the Great Leap Forward in the history of China, there was a continuous increase in cultivated land area. From 1977 to 1984, new agricultural policies and the Household Contract Responsibility System promoted farmers' enthusiasm in land development, which resulted in cultivated land expansion. Grain was still the dominant crop. Agricultural development started to exert pressure on water resources, and reservoirs and channels were constructed to meet the irrigation requirements of large areas of cultivated land. In the main canals and irrigation channels mortar-less cobble protection was used to reduce water leakage. Flood irrigation is the main style, which made water use efficiency very low.

(3) Years 1985-1999 (Stage with significant influence): The Tarim River Basin was designated as one of the foundation areas for high-quality cotton production in China in 1985, which greatly promoted the enlargement of cotton planting. In 1999, the area planted with cotton reached $237.72 \mathrm{hm}^{2}$, which was 4.17 times the area of cotton planting 15 years before. There were obvious changes in the proportions of crops planted. The ratio of areas planted with grain and cotton changed from 85:15 in 1986 to 47:53 in 1999. The irrigation quota of cotton without new water-saving technology was comparatively high, which led to a large increase in water demand. Under the influence of increasing area of cultivated land and the effect of changes in the proportion of crops grown, pressure on water resources caused by agricultural 
development increased significantly. The construction of water conserving infrastructure was accelerated to ensure water volumes for farmland irrigation. By 1999, the percentage of the irrigation area that could be called effective was $94 \%$ and leakage-proofing of channels had been improved to some extent. Flood irrigation was still the main irrigation style, but new water-saving irrigation technology was developed and implemented in local regions.

(4) Years 2000-2009 (Stage with influence adjustment): During this stage, ecological deterioration in the mainstream area of the Tarim River attracted attentions from all sectors of society. To restore the ecosystem, the project to convey water to the dried-up river course in the lower reach of the Tarim River was implemented in 2000. The process of eco-system restoration clearly required the headstream areas to release a certain volume of water into the mainstream of Tarim River. Therefore, agricultural structure in headstream areas was adjusted in this period to control the expansion of the cotton planting area. Replacing cotton with forest fruit was enforced in the Aksu River Basin, which had an obvious influence on the structure of agriculture. The ratios of the areas planted with grain, cotton and forest fruit changed from the ratio of 44:50:6 in 2000 to 29:48:23 in 2009. In the process of expanding the area of forest fruit new water-saving irrigation techniques were not applied over the whole basin. In the perspective of irrigation scheduling, the irrigation requirement of forest fruit was the same as that of cotton, so pressure on surface runoff consumption was not alleviated after this adjustment in agricultural structure. Water resource constraints on agricultural development got worse and worse. Although many measures were implemented to improve agricultural water use efficiency, such as increases in construction of water conservancy projects, improvements to reduce channel seepage rates and development of new water-saving technology, agricultural water use efficiency was still quite low.

\subsection{The relationship between human activities and water resources}

The process of increased runoff consumption with agricultural development in the Aksu River Basin reflects the unbalanced relationship between human ac- tivities and water resources in the Tarim River Basin. In the early stage, humans utilized the water resources to expand agricultural land, which promoted the flourishing of ecologically stable oases (Zhao et al., 2008). However, with the increasing limitation of water resources, disorderly competition for those resources appeared in the whole Tarim River Basin. Excessive exploitation of water in headstream and upstream areas eventually led to ecological damage because of water shortage in the downstream region (Fan, 1993). In addition, in the mainstream of the Tarim River, the range and intensity of disturbance increased because of the human activities (Zhou et al., 2002; Hao et al., 2006).

There are two kinds of reasons for the above change in the human-water relation in the Tarim River Basin. The direct reasons are the rapid expansion of cultivated land induced by population growth and the accelerated increase of planting high water-consuming crops led by the pursuit of high financial benefits. The key reasons are the disorderly competition for water and serious water wastage in agricultural activities. Serious problems existed in water resource management in the Tarim River Basin before 2010. Because the whole Tarim River Basin was covered by 42 counties and 55 regiments, water resource management was carried out in small watersheds and administrative divisions. Although the Administration Bureau of the Tarim River Basin was established in 1992, it only had the right to manage the mainstream. There was no subordinate relationship between the Administration Bureau for the Tarim River Basin and the small watershed administrative divisions, which made it impossible to manage the water resources in the whole river Basin. Piecemeal management led to uncoordinated water right distribution, which, in turn, led to large-scale exploitation of water in the headstreams for local financial interests. As a result, water shortage in the mainstream, downstream and natural ecological system was getting more and more serious. Uncontrolled water resource exploitation could hardly be stopped. Moreover, comparatively low water price could hardly work as an economic lever. Water waste was obvious in the source area where water is easy to be obtained, and it aggravated water resource shortage in the mainstream (Yuan et al., 2010).

Because of the lessons from the continuous 
degradation of the eco-environment in the downstream section of the Tarim River Basin people have come to realize the importance of a balanced relationship between human activities and water resources. People should not only reform water utilization, but also protect the water resources. In 2000 the project of ecological restoration in the Tarim River was started. Although the project aimed to improve agricultural water use efficiency and ecological water transportation to the downstream zone, the conflicts between human activities and water resources were not effectively alleviated because of insufficient water resource management in the whole watershed. Dried-up river courses in the lower reaches could not be avoided. In 2010, government started to integrate water resource administrative divisions. At the same time, agricultural water use efficiency was improved. In 2011, there was no dried up river in the downstream reaches of the Tarim River, and the conflicts between human activities and water resources were alleviated to some extent.

\section{Conclusions}

Quantitative analysis was carried out regarding the influence of the scale of cultivated land area, the mix of major crops and agricultural water use efficiency on the variation of surface runoff in the Aksu River Basin. The results of this analysis show that there were stage characteristics of the influences of these three factors on the reduction of surface runoff. Before 1990, the runoff consumption of agricultural development could be attributed to expansion in the area of cultivated land, with an increase in demand for irrigation water. Since 1990, there has been a continuous expansion in the area of cultivated land and a change in the proportion of area planted with different crops. The domination of grain planting has changed to a domination of cotton and fruit planting. Both the cultivated land expansion and the changes in the crop planting structure have exerted their effects on the rapid reduction of surface runoff. The constraint of water resources on agricultural development has become more and more serious. For the whole basin, many measures have been taken to improve water use efficiency to decrease the pressure on water resources. Though there were some changes, overall water use efficiency was still quite low. In certain localities (such as those managed by First Agricultural Division) there has been apparent improvement in irrigation efficiency, which has alleviated the pressure of agricultural development on runoff consumption. But for most of the region belonging to Aksu Administrative Offices, the irrigation level still needs to be improved greatly to reduce the water demand of agricultural development in the whole river Basin.

Agricultural development has exerted a huge impact on the decrease in surface runoff. Meanwhile, the reduction of surface runoff in the headstreams and mainstream regions also showed a profound effect for the constraint on future agricultural development. On the one hand, there is a sharp conflict in the Aksu River Basin between the comparatively stable surface runoff and the rapidly increased agricultural irrigation water consumption. Here shortage of water resources is the most urgent problem for agriculture. On the other hand, to restore and maintain the ecosystem and production in the mainstream region of the Tarim River, water management of the total catchment and allocation has been enforced in the region in recent years. As the most important headstream for discharge into the mainstream of the Tarim River, water discharge from the Aksu River Basin to the Tarim River should be ensured. The former extensive style of agricultural development should be transformed, and current constraint in water resources should be taken as not only a challenge, but also a chance to carry out this transformation. In addition, effective measures should be taken to control the expansion of cultivated land, optimizing the area planted with different crops and improving agricultural water use efficiency.

\section{Acknowledgements}

This study was funded by the Doctor Western-funded Projects of Chinese Academy of Sciences (XBBS 200803, XBBS 200810), West Plan Foundation of Chinese Academy of Sciences (KZCX2-XB3-01), and the National Natural Science Foundation of China (40801065). 


\section{References}

Administrative Office of Aksu Region and Statistics Bureau of Aksu Region. 1999. Statistical Yearbooks for 50 years of the Aksu region. Urumqi: Xinjiang Statistics Press.

Administrative Office of Aksu Region and Statistics Bureau of Aksu Region. 2000-2010. Statistical Yearbooks of the Aksu Region. Urumqi: Xinjiang Statistics Press.

Chen X. 2008. Land Use/Cover Change in Arid Areas. Beijing: Science Press, 169-180.

Chen Y N, Cui W C, Li W H, et al. 2003. Utilization of water resources and ecological protection in the Tarim River. Acta Geographic Sinica, 58(2): 215-222.

Chen Y N, Zhang X L, Xu H L, et al. 2004. Ecological effect analysis on the water conveyance in dried-up riverway in Tarim River of Xinjiang. Science in China Series D: Earth Sciences, 34(5): 475-482.

Chen Y N, Xu Z X. 2005. Plausible impact of global climate change on water resources in the Tarim River Basin, China. Science in China Series D: Earth Sciences, 48(1): 65-73.

Chen Y N, Takeuchi K, Xu C, et al. 2006a. Regional climate change and its effects on river runoff in the Tarim Basin, China. Hydrological Processes, 20: 2207-2216.

Chen Y N, Zilliacus H, Li W H, et al. 2006b. Ground-water level affects plant species diversity along the lower reaches of the Tarim River, western China. Journal of Arid Environments, 66: 231-246.

Chen Y N, Li W H, Chen Y P, et al. 2007. Water conveyance in dried-up riverway and ecological restoration in the lower reaches of Tarim River, China. Acta Ecologica Sinica, 27(2): 538-545.

Chen Y N, Hao X M, Li W H, et al. 2008. An analysis of the ecological security and ecological water requirements in the inland rivers of arid regions. Advances in Earth Science, 23(7): 732-738.

Chen Y N, Ye Z X, Mao X H, et al. 2009. Dried-up trend of Tarim River and the countermeasures for mitigation. Arid Land Geography, 32(6): 813-820.

Chen Z S, Chen Y N, Cao Z C, et al. 2011. The change of annual runoff and its connectivity with human driving factors in the mainstream of the Tarim River. Scientia Geographica Sinica, 31(12): 1506-1511.

Deng M J. 2005. Eco-environmental responses of the lower reaches of Tarim River to the emergency water deliveries. Advances in Water Science, 16(4): 586-591.

Deng M J. 2009. Theory and Practice of Water Control in Tarim River, China. Beijing: Science Press, 63.

Duan J J, Wang Y G, Wang X F, et al. 2001. Impact of climate change and human activities on the water resources and ecological environments in the Tarim River Basin in 1957-2006. Journal of Glaciology and Geocryology, 31(5): 781-791.

Fan Z L. 1993. A study on the formation and evolution of oases in
Tarim Basin. Acta Geographica Sinica, 48(5): 421-427.

Fu L X, Chen Y N, Li W H, et al. 2009. Analyses of the duration and tendency of annual runoff in the headwaters of the Tarim River in the recent 50 years. Journal of Glaciology and Geocryology, 31(3): 457-463.

Gou S S, Zhang X W, Wang Y G, et al. 2010. Analysis on runoff volumes, water quality and water consumption of the Tarim River in recent 50 years. Arid Zone Research, 27(6): 861-870.

Hao X M, Chen Y N, Li W H. 2006. The driving forces of environmental change during the last 50 years in the Tarim River Basin. Acta Geographica Sinica, 61(3): 262-272.

Hao X M, Chen Y N, Xu C. 2008. Impacts of climate change and human activities on the surface runoff in the Tarim River Basin over the last fifty years. Water Resources Management, 22: 1159-1171.

Hao X M, Li W H, Chen Y N, et al. 2008. The factors discrimination of human activities and climate change for the mainstream of Tarim River. Progress in Natural Science, 18(12): 1409-1416.

Jiang Y, Zhou C H, Cheng W M. 2005. Analysis on runoff supply and variation characteristics of the Aksu Drainage Basin. Journal of Natural Resources, 20(1): 28-34.

Jiang Y, Zhou C H, Cheng W M. 2007. Streamflow trends and hydrological response to climatic change in Tarim Headwater Basin. Journal of Geographical Sciences, 17(1): 51-61.

Li W H, Chen Y J, Chen Y P, et al. 2006. Effects of ecological stream water transfusion on groundwater level and quality in the lower reaches of the Tarim River. Resources Science, 28(5): 157-163.

Ma X D, Chen Y N, Zhu C G, et al. 2011. The variation in soil moisture and the appropriate groundwater table for desert riparian forest along the Lower Tarim River. Journal of Geographical Sciences, 21(1): 150-162.

Mansue S, Hu J L. 2011. Land use change in the Aksu River Basin in 1957-2007 and its hydrological effect analysis. Journal of Glaciology and Geocryology, 23(1): 182-189.

Mao D H. 1998. The Water Resources, Environment and Management of Tarim River Watershed. Beijing: China Environmental Science Press, 185-186.

Mtalip T, Yang H M, Zhao X F. 2009. Discussion on current situation of water resource in the upper reaches of the Tarim River Mainstream. Environmental Protection of Xinjiang, 31(3): 6-9.

Paul A S, William D N. 2004. Microeconomics. Beijing: Posts \& Telecommunications Press, 51-53.

Song Y D, Fan Z L, Lei Z D. 1999. Research on Water Resources Ecology of Tarim River, China. Urumqi: Xinjiang People Press, 7.

Statistical Bureau of Xinjiang Uygur Autonomous Region. 2005. Statistical Yearbooks from 1955 to 2005 of Xinjiang Uygur 
autonomous region. Beijing: China Statistics Press.

Statistical Bureau of Xinjiang Uygur Autonomous Region. 1981-2010. Statistical Yearbook of Xinjiang. Beijing: China Statistics Press.

Statistics Bureau of Xinjiang Production and Construction Corps. 1990-2010. Statistical Yearbooks of Xinjiang Production and Construction Corps. Beijing: China Statistics Press.

Wang G Y, Shen Y P, Su H C, et al. 2008. Runoff changes in Aksu River Basin during 1956-2006 and their impacts on water availability for Tarim River. Journal of Glaciology and Geocryology, 30(4): 562-568.

Wang J, Liu X, Gong W H, et al. 2010. Streamflow variations and flow-break causes of four source rivers and mainstream of Tarim River, Xinjiang in 2008. Journal of Glaciology and Geocryology, 32(3): 593-601.

Wang J, Zhang X W, Liu X, et al. 2009. Water supplying and conveying from the four source streams to the mainstream of Tarim River in 2007. Journal of Glaciology and Geocryology, 31(4): 732-740.

Wang Q M, Zhang J B, Fu Y C. 2010. Runoff change and its influencing factors under changing environment in Tarim River. Bulletin of Soil and Water Conservation, 30(4): 99-109.

Wang R H, Fan Z L. 2004. Evidence for a warm-humid climate in arid northwestern China during 40-30ka BP. Quaternary Science Reviews, 26(6): 1-12.

Water Resources Bureau in Xinjiang Uygur Autonomous Region. 1993. Xinjiang Irrigation. Urumqi: Xinjiang People Press, $102-110$.

Water Resources Bureau in Xinjiang Uygur Autonomous Region. 2007-2010. Xinjiang Water Resource Bulletins. Urumqi: Water Resources Bureau in Xinjiang Uygur Autonomous Region.

Xi X M, Duan S G. 2009. Water consumption analysis and cause of the middle reaches in Tarim River. Water and Soil Conservation, 16(3): 34-37.

Xia J, Sun X T, Tan G. 2003. Advances and prospective about water cycle research in West China. Advances in Earth Science, 18(1): 58-67.

Xu H L, Ye M, Song Y D, et al. 2005. The dynamic variation of water resources and its tendency in Tarim River Basin. Acta Geographica Sinica, 60(3): 487-494.

$\mathrm{Xu} \mathrm{H} \mathrm{L,} \mathrm{Ye} \mathrm{M,} \mathrm{Li} \mathrm{J} \mathrm{M.} \mathrm{2008.} \mathrm{The} \mathrm{water} \mathrm{transfer} \mathrm{effects} \mathrm{on} \mathrm{agri-}$ cultural development in the lower Tarim River, Xinjiang of China. Agricultural Water Management, 95: 9559-9568.

Ye Z X, Chen Y N, Li W H. 2010. Ecological water demand of natural vegetation in the lower Tarim River. Journal of Geographical Sciences, 20(2): 261-272.

Yu Y, Huang L M, Shen B, et al. 2009. Current situation analysis of water consumption in Hotan River Basin. Journal of Water Resources and Water Engineering, 20(6): 47-51.

Yuan X. 2010. Discussion on the mechanism of water resources management system in Tarim River Basin. China Water Resources, (7): 23-25.

Zhang Z J, Li J M, Shi S B, et al. 2008. Fuzzy-based evaluation of water resources carrying capacity in Aksu River. Journal of Arid Land Resources and Environment, 22(7): 138-143.

Zhao W Z, Zhuang Y L. 2008. Study on the stability of oases in the arid areas in China. Arid Zone Research, 25(2): 155-162.

Zhou H, Qin J L, Wei J Y. 2002. Estimated calculation to annual runoff values of Tarim River affected by human activities. Arid Land Geography, 25(1): 70-74.

Zhou X M, Chen Y N, Li W H, et al. 2008. Analysis of socio-economic factors related to ecosystem degradation in the lower reaches of the Tarim River in the last 50 years. Resources Science, 30(9): 1389-1396.

Zhu X M. 2001. Adapting new measures to strengthen comprehensive rehabilitation in Tarim River Basin in the new situation. China Water Resources, 9: 50-52.

Zuo Q T. 2006. The strategically important green corridor in the downstream of Tarim River was almost destroyed. Scientia Geographica Sinica, 26(5): 564-568. 